\title{
Ultrasensitive Detection of Ebola Virus Oligonucleotide Based on Upconversion Nanoprobe/Nanoporous Membrane System
}

Ming-Kiu Tsang ${ }^{1, \$}$, WeiWei Ye $e^{2,3, \$}$, Guojing Wang ${ }^{4}$,Jingming Li $^{4}$, Mo Yang ${ }^{3 *}$, Jianhua Hao ${ }^{1 *}$

${ }^{1}$ M.-K. Tsang ${ }^{\$}$ and Prof. J. H. Hao*, Department of Applied Physics, The Hong Kong Polytechnic University, Hung Hom, Kowloon, Hong Kong, P. R. China

${ }^{2}$ W. W. Ye ${ }^{\$}$, Institute of Ocean Research, Zhejiang University of Technology, Hangzhou, Zhejiang 310014, P. R. China

${ }^{3}$ W. W. Ye ${ }^{\$}$ and Prof. M. Yang*, Interdisciplinary Division of Biomedical Engineering, The Hong Kong Polytechnic University, Hung Hom, Kowloon, Hong Kong, P. R. China

${ }^{4}$ G. Wang and J. Li, National Center for Clinical Laboratory, Beijing Hospital of the Ministry of Health, No. 1 Dahua Road, Dongdan, Beijing 100730, P. R. China

${ }^{\$}$ Author Contributions: Ming-Kiu Tsang and WeiWei Ye contributed equally to this work 


\section{Table of Contents}

1. Materials and methods

1.1 Materials

1.2 Preparation of gold nanoparticles

1.3 Conjugation of Ebola virus oligonucleotide (oligo) with AuNPs

1.4 Surface modification of nanoporous alumina membrane

1.5 Homogeneous detection

1.6 Upconversion quenching measurement

1.7 RNA extraction from inactivated Ebola particles

2. Supplementary information and figures

S1 Characterizations of PEI-BaGdF $5: \mathrm{Yb} / \mathrm{Er}$ UCNPs

S2 STEM and the elemental mapping of UCNPs

S3 Morphology of NAAO membrane and EDX scan of UCNPs on NAAO membrane

S4 XRD patterns of UCNPs, probe-modified and hybridized structure on NAAO

S5 FTIR and Zeta potential of UCNPs and AuNPs 
S6 Upconversion luminescence property of UCNPs

S7 Localized plasmonic absorption of AuNPs

S8 XPS scan of UCNPs-Ebola virus oligo-AuNPs

S9 Upconversion enhancement of UCNPs on NAAO membrane

S10 Characterizations of homogeneous LRET assay

\section{References}

\section{Materials and methods}

1.1 Materials: $\mathrm{Ln}\left(\mathrm{NO}_{3}\right)_{3} \cdot 6 \mathrm{H}_{2} \mathrm{O}(\mathrm{Ln}=\mathrm{Gd}, \mathrm{Yb}, \mathrm{Er})$ compounds were purchased from Sigma Aldrich and dissolved in de-ionized (DI) water to form solutions with concentrations of 0.5 $\mathrm{M} \mathrm{Gd}\left(\mathrm{NO}_{3}\right)_{3}, \mathrm{Yb}\left(\mathrm{NO}_{3}\right)_{3}$ and $0.1 \mathrm{M} \mathrm{Er}\left(\mathrm{NO}_{3}\right)_{3}$. Ethylene glycol (EG, $\left.99 \%\right)$ and branched polyethylenimine (PEI, $25 \mathrm{kDa}$ ) were purchased from Sigma-Aldrich. $\mathrm{NH}_{4} \mathrm{~F}(99.99 \%)$ and $\mathrm{BaCl}_{2}(99.99 \%)$ were obtained from Sinopharm Chemical Reagent Co., China. Gold (III) chloride trihydrate $\left(\mathrm{HAuCl}_{4} \cdot 3 \mathrm{H}_{2} \mathrm{O}\right)$ and sodium citrate solution were purchased from Sigma Aldrich. Nanoporous alumina (NAAO) membranes (Whatman) were purchased from GE Healthcare Life Sciences. Hydrogen peroxide was purchased from Advanced Technology \& Industrial Co., Ltd., and (3-aminopropyl)trimethoxysilane) (APTES) and acetaldehyde (99 \%) 
was obtained from Sigma Aldrich. Acetone (99.5 \%) was from Acros Organics (Thermo Fisher Scientific, Geel, Belgium). Glutaraldehyde (25\% in $\left.\mathrm{H}_{2} \mathrm{O}\right)$, 3-Mercaptopropionic acid (HS- $\left.\mathrm{C}_{2} \mathrm{H}_{4}-\mathrm{COOH}\right)$ (99\%) and N-(3-Dimethylaminopropyl)-N'-ethylcarbodiimide (EDC) were purchased from Sigma Aldrich. All of these chemicals were used as received without further purification.

1.2 Preparation of gold nanoparticles: Gold nanoparticles (AuNPs) were prepared following the procedures described in our previous study. ${ }^{1}$ Briefly, a mixture of $\mathrm{HAuCl}_{4}$ solution $(3 \mu \mathrm{L}, 14.3 \mathrm{wt} \%)$ and DI water $(10 \mathrm{~mL})$ was boiled in beakers that were washed thoroughly in aqua regia (mixture of $\mathrm{HCl}$ and $\mathrm{HNO}_{3}$ with the ratio of 3:1) and rinsed in DI water. With vigorous stirring, sodium citrate solution $(1 \mathrm{~mL}, 1 \mathrm{wt} \%)$ was added to the boiling solution within $1 \mathrm{sec}$. The solution color changed from pale yellow to wine red in a few min. It continued to boil for 15 min and was left to cool down to room temperature with stirring.

1.3 Conjugation of Ebola virus oligonucleotide with AuNPs: Thiol modified Ebola virus oligonucleotide (short segment: 5'-thiol-GGACCGCCAAGGTAAAAAATGAGGT-3', 25-base, M233114.1), FAM modified oligonucleotide (5'-thiol-GGACCGCCAAGG TAAAAAATGAGGT-FAM-3' $)^{2} \quad$ another non-target oligonucleotide (S1:5'-thiol-CCTGGCGGTTCCATTTTTTACTCCA-3') and 3-base mismatch 
oligonucleotide (S2: 5'-thiol-GGACCGGCAAGGAAAAAATTGAGGT-3') were synthesized by Integrated DNA Technologies (IDT) Inc. (Coralville, IA). Thiol modified oligonucleotides were activated by DTT $(0.1 \mathrm{M}, \mathrm{pH} 8.2)$ and purified by gel columns (illustra MicroSpin G-25 Columns, GE Healthcare, UK) based on the manufacturer's instructions. It was characterized by UV-visible spectrophotometer (Ultrospec 2100 pro). Thiol modified Ebola gene oligonucleotides were mixed with AuNPs and incubated for $24 \mathrm{~h}$ at room temperature. Sodium solution $\left(0.1 \mathrm{M} \mathrm{NaCl}, 5 \mathrm{mM} \mathrm{NaH} \mathrm{PO}_{4}\right)$ was added to age for $16 \mathrm{~h}$. The excess oligonucleotides were removed by centrifugation for $30 \mathrm{~min}$ at a high speed of 13,200 rpm. The remaining red oily precipitate was collected and washed by PBS solution for 3 times. Finally, it was suspended in PBS. The complementary oligo was added to the AuNPs-Ebola virus oligo conjugation system and incubated for $30 \mathrm{~min}$ to ensure full hybridization. The unreacted single-stranded oligo was removed by centrifugation. The double-stranded oligo and AuNPs conjugation was incubated in oven at different temperatures for $5 \mathrm{~min}$ and the UV absorbance at $260 \mathrm{~nm}$ was measured by UV-visible spectrophotometer.

\subsection{Surface modification of nanoporous alumina membrane: Nanoporous alumina} (NAAO) membranes with a pore diameter of $100 \mathrm{~nm}$ were preprocessed according to the procedures of surface modification in our previous studies. ${ }^{3,4}$ NAAO membrane surfaces 
were cleaned and hydroxyl groups were generated on the surfaces by boiling in hydrogen peroxide for $30 \mathrm{~min}$ and rinsing in DI water with gentle shaking for $15 \mathrm{~min}$. Dried membranes were immersed in a solution of APTES and acetone (2\% APTES) for $1 \mathrm{~h}$ and followed by washing with acetone (12 times, 5 min each). ${ }^{5}$ The silane linkage was cured under $110^{\circ} \mathrm{C}$ for $1 \mathrm{~h}$. PEI modified UCNPs were dissolved in PBS (pH 7.4, $10 \mathrm{mM}$ ) with the concentration of $10 \mathrm{mg} / \mathrm{mL}$, followed by addition of $2 \mu 1$ glutaraldehyde to the mixture. The mixture was shaken for $1 \mathrm{~h}$ at room temperature to ensure thorough reaction. It was centrifuged and washed by PBS for 3 times to remove excess glutaraldehyde and resuspended in PBS. The functionalized UCNPs were added to APTES modified NAAO membrane and stayed overnight. UCNPs were conjugated on NAAO membrane by glutaraldehyde linkage between amino groups. Acetaldehyde solution (2\%) was used to rinse the NAAO membrane immobilized with glutaraldehyde modified UCNPs to react with the remaining amino groups on membrane surface. Amino modified oligonucleotide probes (5'-amino-ACCTCATTTTTTACCTTGGCGGTCC-3', $5 \mu \mathrm{M}$ ) were covalently conjugated to UCNPs on NAAO membrane using glutaraldehyde as the linkage.

\subsection{Homogeneous detection: PEI modified $\mathrm{BaGdF}_{5}: \mathrm{Yb} / \mathrm{Er}$ UCNPs was covalently} conjugated with amino modified oligonucleotide probe (5'-aminoACCTCATTTTTACCTTGGCGGTCC -3') (5'-amino- 
ACCTCATTTTTTACCTTGGCGGTCC -FAM-3') by covalent bond with glutaraldehyde as the cross linker. $2 \mathrm{mg}$ UCNPs were thoroughly dispersed in $200 \mu \mathrm{l}$ of PBS (pH 7.4, $10 \mathrm{mM}$ ). UCNPs were added to glutaraldehyde $(5 \%, 1 \mathrm{~mL})$ and left reaction with gentle shaking for 1 $\mathrm{h}$ at $25^{\circ} \mathrm{C}$. The glutaraldehyde-activated UCNPs were washed and resuspended in $200 \mu \mathrm{l}$ of the same PBS. Amino modified oligonucleotides $(100 \mu \mathrm{M})$ were incubated with glutaraldehyde-activated UCNPs. FAM modified oligos $(5 \mu \mathrm{M}, 100 \mu \mathrm{L})$ were conjugated on UCNPs (10 mg/mL, $50 \mathrm{uL})$ and centrifuged. Supernatant was collected and diluted to $100 \mu \mathrm{L}$ for fluorescence intensity measurement. Fluorescence intensity was measured by microplate reader (Infinite F200, Tecan, Switzerland). Various concentrations of Ebola virus oligonucleotides conjugated with AuNPs were mixed with $\mathrm{BaGdF}_{5}: \mathrm{Yb} / \mathrm{Er}$ UCNPs-oligo $(0.2$ $\mathrm{mg} / \mathrm{mL}$ ) and incubated for $2 \mathrm{~h}$ at $25{ }^{\circ} \mathrm{C}$ to make sure the full hybridization of Ebola virus oligonucleotides and their probes. The mixture was subjected to for LRET measurement using FLSP920 Edinburgh analytical instrument. All the various upconversion luminescence spectra were measured with the same experimental condition.

1.6 Upconversion quenching measurement: To investigate the luminescence quenching efficiency, the prepared AuNPs-Ebola target oligo conjugation was incubated with modified NAAO membranes for $2 \mathrm{~h}$ at room temperature to ensure complete hybridization between Ebola target oligonucleotides with probes. The hybridization process brought AuNPs and 
UCNPs into close proximity on membranes. NAAO membrane immobilized with UCNPs-probe oligo was fixed on the measuring stage of FLSP920 Edinburgh analytical instrument for photoluminescence measurement with the center point and surrounding four points detected. The same detecting procedure was applied for photoluminescence measurement after various concentrations of target oligos conjugated with AuNPs hybridization with probe oligo on NAAO membrane. The photoluminescence intensity of each concentration was averaged by the data obtained from five points. With $980 \mathrm{~nm}$ diode laser excitation, the visible emissions from UCNPs were absorbed by AuNPs, and then the quenched upconversion LRET spectra were obtained.

1.7 RNA extraction from inactivated Ebola virus particles: Inactivated Ebola virus particles were obtained from Beijing Hospital (Beijing, China) with purified RNA target fragments (2400bp, 3'-untranslated region (UTR) and a large part of the NP region). ${ }^{6}$ Nucleotide sequences of the epidemic strain of Zaire Ebola virus from West Africa were obtained from GenBank KJ660346, KJ660347 and KJ 660348. The detailed preparation procedures for Ebola virus particles were based on the protocols for external quality assessment (EQA) of Ebola virus molecular detection in China established by National Center for Clinical Laboratories (NCCL) of China., ${ }^{5,6}$ Generally, Zaire (Mayinga) Ebola virus from infected Vero E6 pellets was suspended in $50 \mathrm{mM}$ sodium borate and gamma 
irradiated on dry ice and sonicated to get inactivated and highly disrupted viral particles. To purify the inactivated viral particles, the cell supernatants were pelleted over a $20 \%$ sucrose cushion and then further purified on a $10-60 \%$ sucrose gradient. The gradient fraction containing the inactivated viral particles was then collected. To extract the viral oligo, inactivated virus particles were mixed with human serum from human male $\mathrm{AB}$ plasma (Sterile-filtered, Sigma Chemical Co.). Total oligonucleotide fragments were extracted and fragmented from the above sample $(200 \mu \mathrm{L})$ using a PureLink Viral RNA kit (Life Technologies) with RNA fragmentation reagents according to procedures. The extracted oligonucleotides were eluted in $30 \mu \mathrm{L}$ sterile, RNase-free water and detected by the biosensor without thiol modification. The target oligonucleotides contain a fragment with the sequence: 5'-GGACCGCCAAGGTAAAAAATGAGGT-3', which led to the hybridization with the probe immobilized on UCNPs.

1.8 Extracted Viral RNA-AuNP conjugation: AuNPs were functionalized with 3-Mercaptopropionic acid ( $\mathrm{HS}-\mathrm{C}_{2} \mathrm{H}_{4}-\mathrm{COOH}$ ) by covalent bonding between AuNP and thiol group of the linker. RNA extracted from inactivated Ebola virus particles were conjugated on functionalized AuNPs by EDC activation. 3-Mercaptopropionic acid solution (6 $\mu \mathrm{M}, 5 \mu \mathrm{l})$ was slowly added into AuNPs solution $(6 \mathrm{nM}, 100 \mu \mathrm{l})$ and incubated for $10 \mathrm{~h}$ at $4{ }^{\circ} \mathrm{C}$. The excess linker molecules were removed by centrifugation. The remaining functionalized 
AuNPs were collected and redispersed in sterilized PBS. The extracted RNA (10 $\mu \mathrm{l})$ was added to conjugate on functionalized AuNPs for detection. 

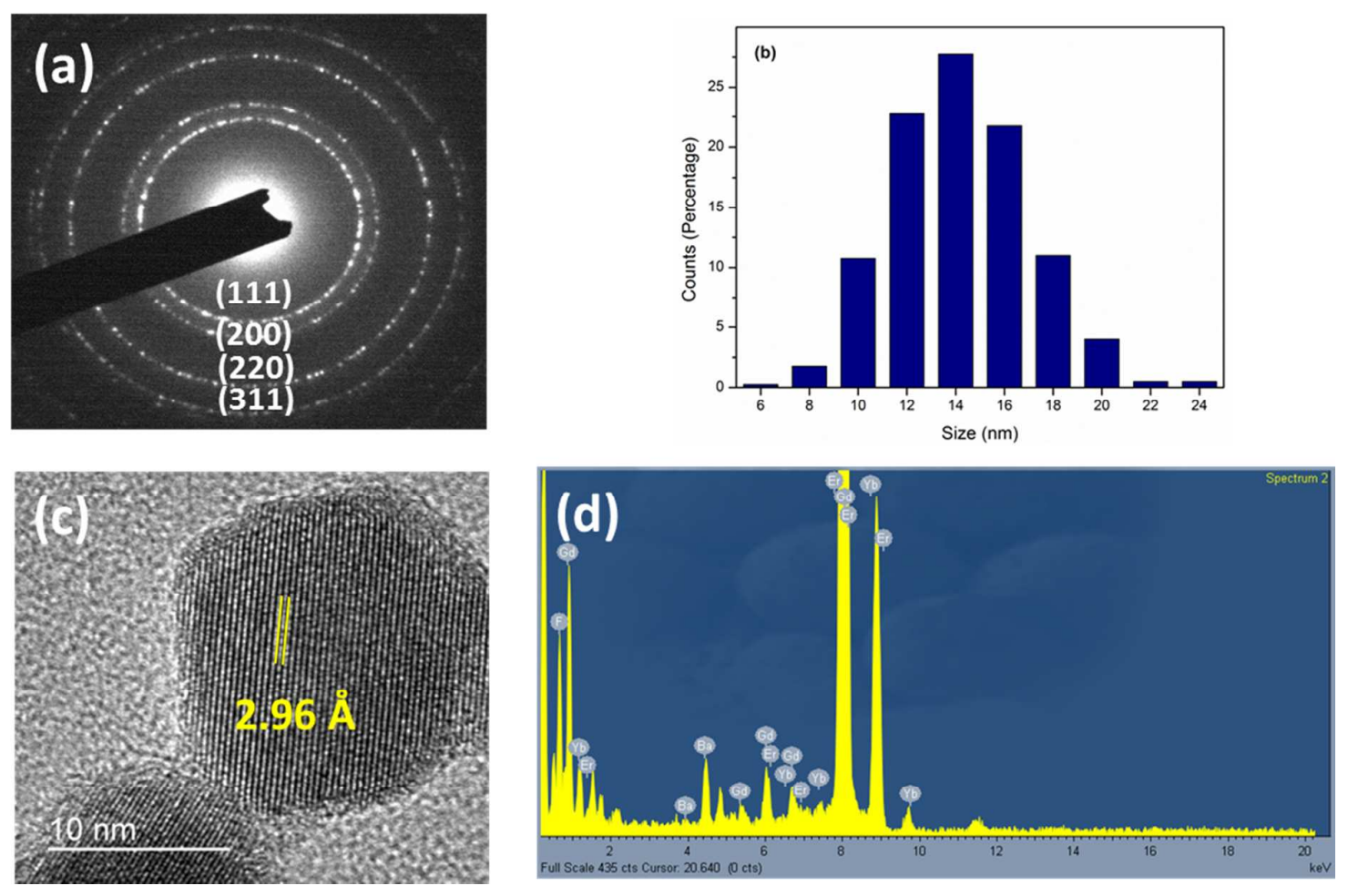

Figure S1. (a) SAED; (b) Size distribution; (c) HRTEM and (d) EDX of PEI-modified $\mathrm{BaGdF}_{5}: \mathrm{Yb} / \mathrm{Er}$ UCNPs. The SAED pattern in Figure S1(a) reveals a simple cubic phase structure of the UCNPs while Figure S1(b) shows that the UCNPs present an average size of about $14 \mathrm{~nm}$. Moreover, clear lattice fringes are observed in Figure S1(c), the measured fringe separation is about $2.96 \AA$. The value is close to (200) plane of $\mathrm{BaGdF}_{5}$ and hence this indicates good crystallinity of the as-synthesized UCNPs. In addition to the structural information, the chemical composition of the UCNPs was studied by using EDX and elemental mapping. The EDX spectrum (Figure S1(d)) indicates that the UCNPs are consisted of $\mathrm{Ba}, \mathrm{Gd}, \mathrm{F}, \mathrm{Yb}$ and Er. This is consistent with the designed chemical composition of $\mathrm{BaGdF}_{5}: \mathrm{Yb} / \mathrm{Er} \mathrm{UCNPs}$. 

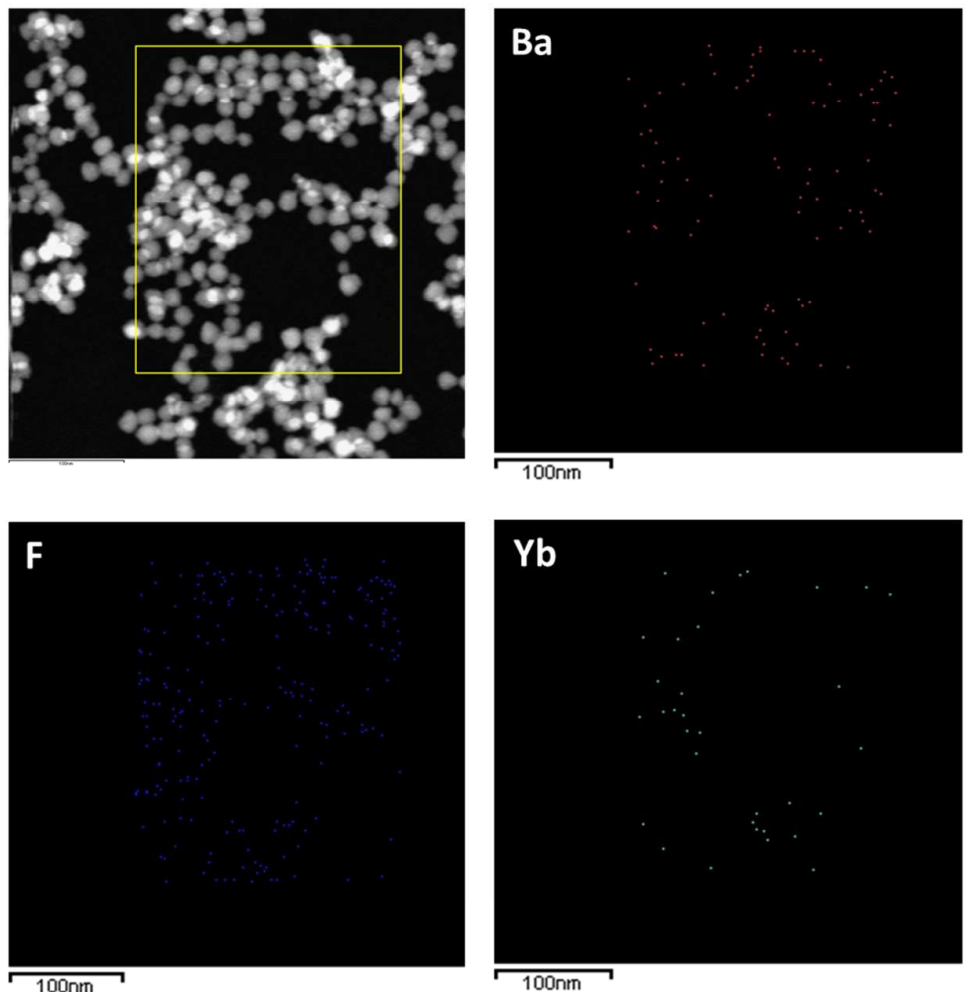

$100 \mathrm{~nm}$

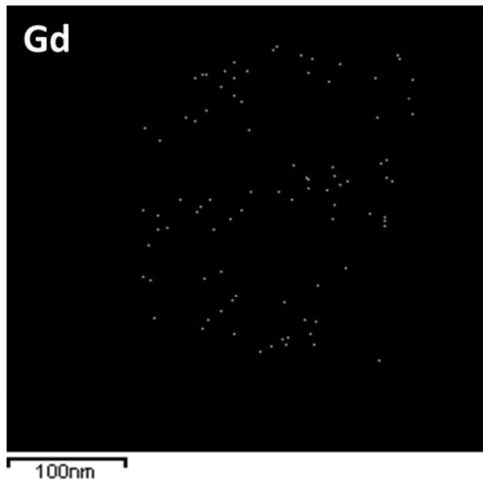

Er

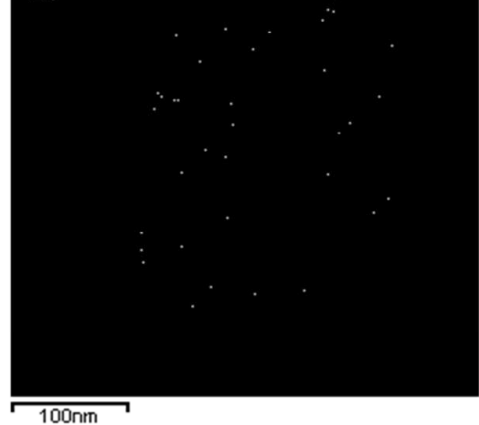

Figure S2. STEM and the elemental mapping for $\mathrm{Ba}, \mathrm{Gd}, \mathrm{F}, \mathrm{Yb}$ and $\mathrm{Er}$ of $\mathrm{BaGdF}_{5}: \mathrm{Yb} / \mathrm{Er}$

UCNPs. The scanning TEM (STEM) of the UCNPs is captured prior to elemental mapping.

The yellow frame in the STEM image shows the mapping area. Then, the mapping was carried out in five channels with different colors. The amount of color dots represents the respective amount of elements in each channel. Among them, the fluorine channel (blue) results in the most amount of signals because fluorine is the most abundant in $\mathrm{BaGdF}_{5}: \mathrm{Yb} / \mathrm{Er}$ UCNPs. 

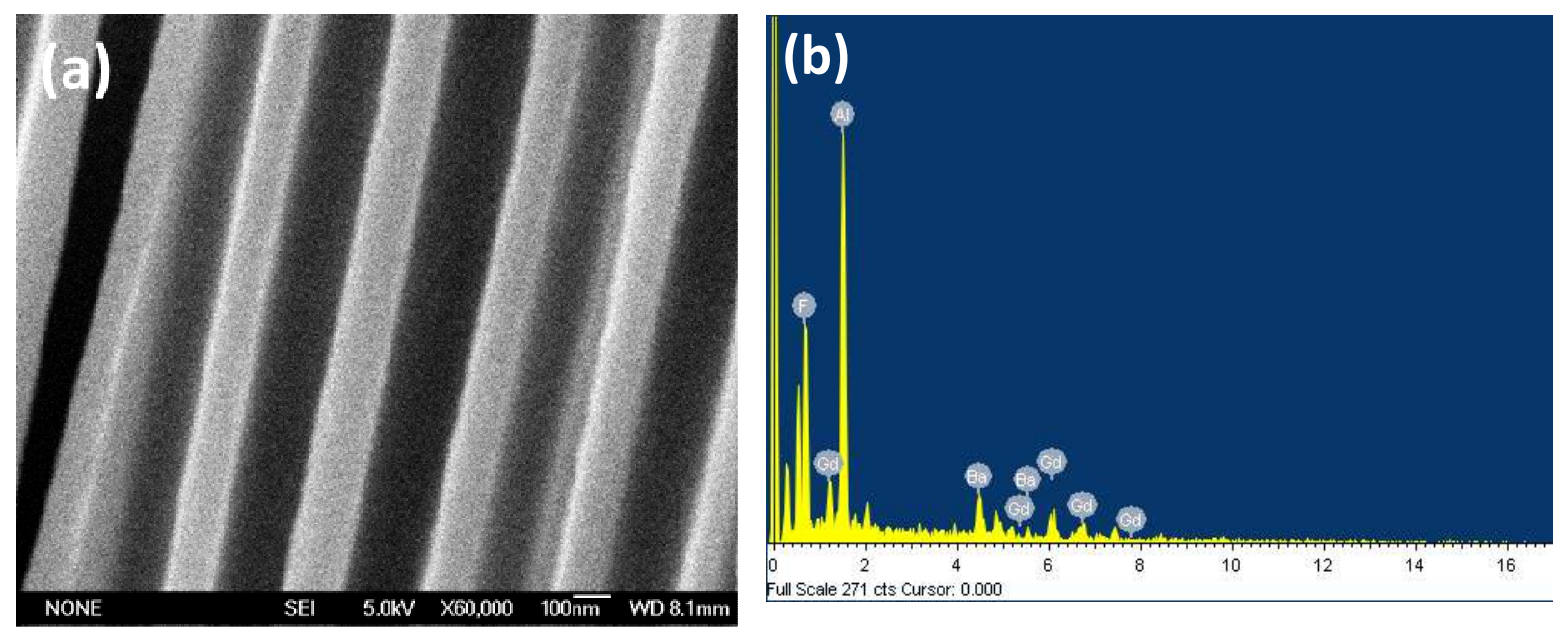

Figure S3. (a) Typical morphology of the NAAO array structure and (b) EDX area scan of the probe-modified UCNPs of the NAAO membrane. The cross-sectional view of the NAAO pillows can be clearly observed in the FE-SEM picture. Meanwhile, the EDX spectrum shows the essential elements on the probe-modified UCNPs immobilized on NAAO pillows, such as $\mathrm{Gd}, \mathrm{Al}, \mathrm{Yb}$ and $\mathrm{F}$. Noted that the EDX technique is not applicable to the precise measurement of light elements in the complementary oligo probe. 


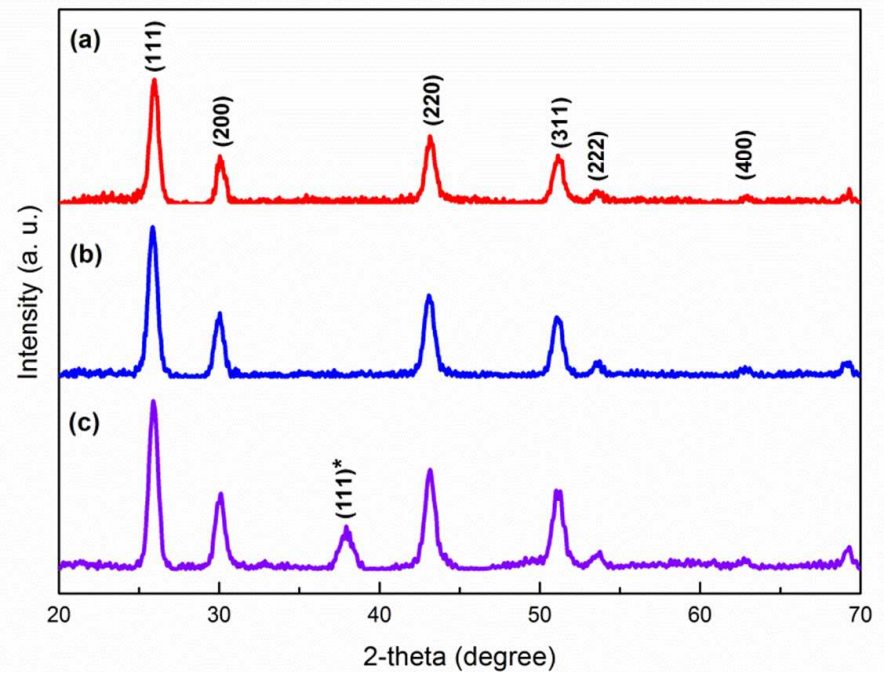

Figure S4. XRD pattern of (a) PEI-modified $\mathrm{BaGdF}_{5}: \mathrm{Yb} / \mathrm{Er}$ UCNPs, (b) Probe-modified $\mathrm{BaGdF}_{5}: \mathrm{Yb} / \mathrm{Er}$ UCNPs and (c) Probe-Ebola virus oligo hybridized $\mathrm{BaGdF}_{5}: \mathrm{Yb} / \mathrm{Er} \mathrm{UCNPs}$. The extra diffraction peak is due to the AuNPs on the Ebola oligo target. 

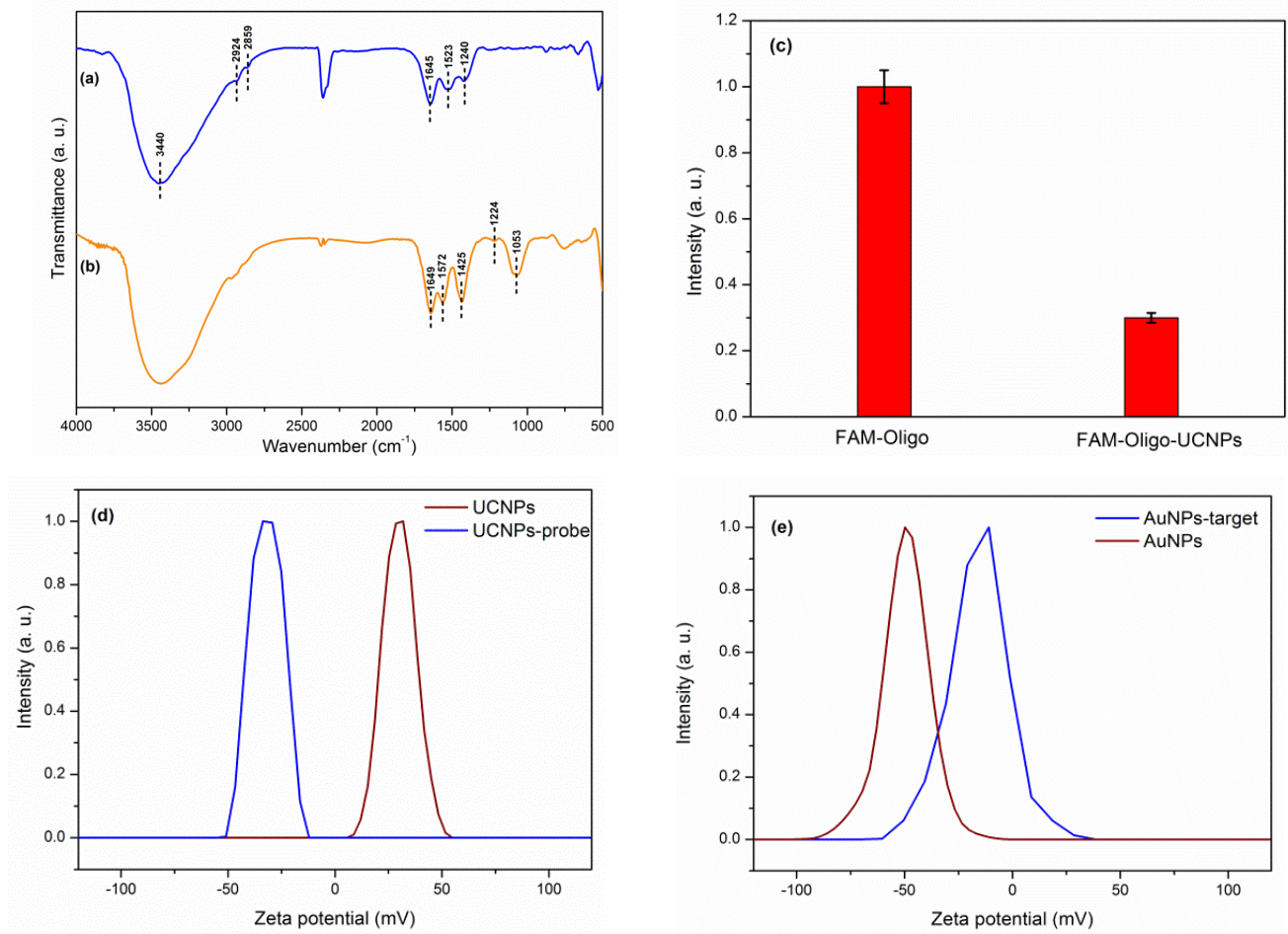

Figure S5 FTIR spectrum of (a) PEI-modified; (b) probe modified $\mathrm{BaGdF}_{5}: \mathrm{Yb} / \mathrm{Er}$ UCNPs;

(c) Fluorescence intensity of FAM modified oligo and UCNPs conjugated FAM-oligo; Zeta

potential of (d) PEI-modified and probe modified $\mathrm{BaGdF}_{5}: \mathrm{Yb} / \mathrm{Er}$ UCNPs; (e) Citrate-modified and target modified AuNPs. In Figure S5(a), the UCNPs display broad absorption peak around $3440 \mathrm{~cm}^{-1}$, which is attributed to the $\mathrm{O}-\mathrm{H} / \mathrm{N}-\mathrm{H}$ stretching vibration. Meanwhile, the peaks at 2924, 2859 and $1240 \mathrm{~cm}^{-1}$ are due to stretching vibration of the C-N group. The peaks around $1523 \mathrm{~cm}^{-1}$ and $1645 \mathrm{~cm}^{-1}$ are ascribed to the $\mathrm{N}-\mathrm{H}$ bending mode of amino groups. Hence, these data primarily confirm the capping of PEI molecules on the surface of the UCNPs. ${ }^{7,8}$ After modifying the probe oligo on the surface of UCNPs, the new 
bands at $1053 \mathrm{~cm}^{-1}$ and $1224 \mathrm{~cm}^{-1}$ can be observed due to $\mathrm{C}-\mathrm{O}$ ribose and phosphate, respectively. The appearance of peaks at $1425 \mathrm{~cm}^{-1}, 1572 \mathrm{~cm}^{-1}$, and $1649 \mathrm{~cm}^{-1}$ are the characteristic vibration bands of guanine base, cytosine base, and adenine base, respectively (Figure S5(b)). ${ }^{9}$ 

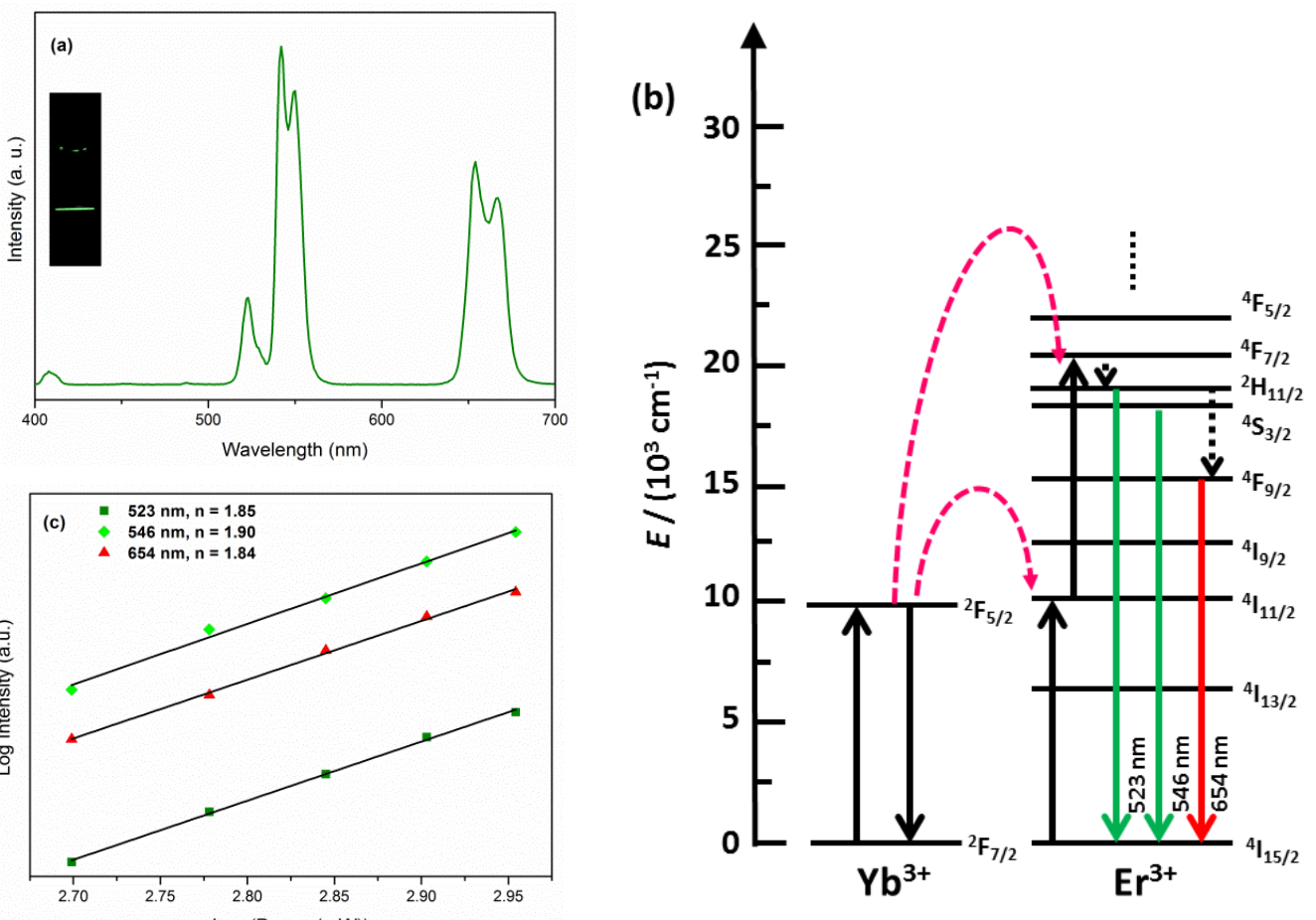

Figure S6. (a) UC emission spectrum of PEI-modified $\mathrm{BaGdF}_{5}: \mathrm{Yb} / \mathrm{Er}$ UCNPs (Inset: photography showing intense green UC emission excited by $980 \mathrm{~nm}$ diode laser); (b) Simplified energy level diagram of $\mathrm{Yb} / \mathrm{Er}$ (c) Incident power dependence study of PEI-modified $\mathrm{BaGdF}_{5}: \mathrm{Yb} / \mathrm{Er}$ UCNPs. Owing to the small size and good water dispersity of the PEI-modified UCNPs, a stable and transparent colloidal solution was formed. When the UCNPs were excited by $980 \mathrm{~nm}$ CW laser, the UCNPs emitted intense green UCL by naked eyes (inset of Figure S6(a)). The corresponding UC spectrum (Figure S6(a)) suggests that the UCL is arisen from three main peaks at 523, 546 and $654 \mathrm{~nm}$. The existence of such emission peaks can be deducted from the simplified energy level diagram of $\mathrm{Yb} / \mathrm{Er}$ (Figure S6(b)). The three emission bands are due to the intra $4 \mathrm{f}-4 \mathrm{f}$ electronic transitions from ${ }^{2} \mathrm{H}_{11 / 2} /{ }^{4} \mathrm{~S}_{3 / 2} \rightarrow{ }^{4} \mathrm{I}_{15 / 2}$ and ${ }^{4} \mathrm{~F}_{9 / 2} \rightarrow{ }^{4} \mathrm{I}_{15 / 2}$. To further explore the UCL mechanism of the $\mathrm{Yb} / \mathrm{Er}$ 
system, the incident power dependence of the green and red emission bands are studied according to the power law for UCL: $\mathrm{I}_{\mathrm{UC}} \alpha \mathrm{I}^{\mathrm{n}}{ }_{\mathrm{IR}} \cdot{ }^{10}$ Figure S6(c) shows the log-log plot of the UCL intensity against the NIR excitation and the slope values for the three bands are 1.85 , 1.90 and 1.84 , respectively. Therefore, the results indicate that the three UCL emissions are originated from two-photon UC process. 


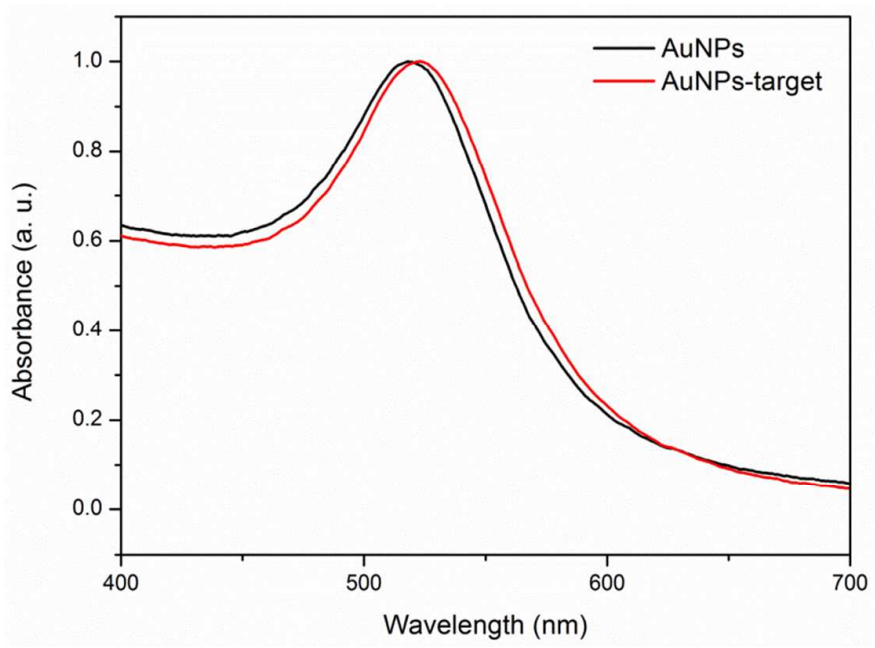

Figure S7. Optical absorption characteristics of AuNPs and the shift in absorption peak of the sample after Ebola virus oligo target is conjugated. After the conjugation of the target oligo, the peak shifts slightly towards long wavelength. This is due to the conjugation of Ebola oligo onto AuNPs. At any rate, the absorption band overlaps with the UCL band of the UCNPs well. This implies that the UCL from the UCNPs could be effectively quenched by the AuNPs when they were in close proximity. In fact, such characteristics manifest the energy transfer of the homogeneous and heterogeneous biosensor for the detection of Ebola virus oligo. 

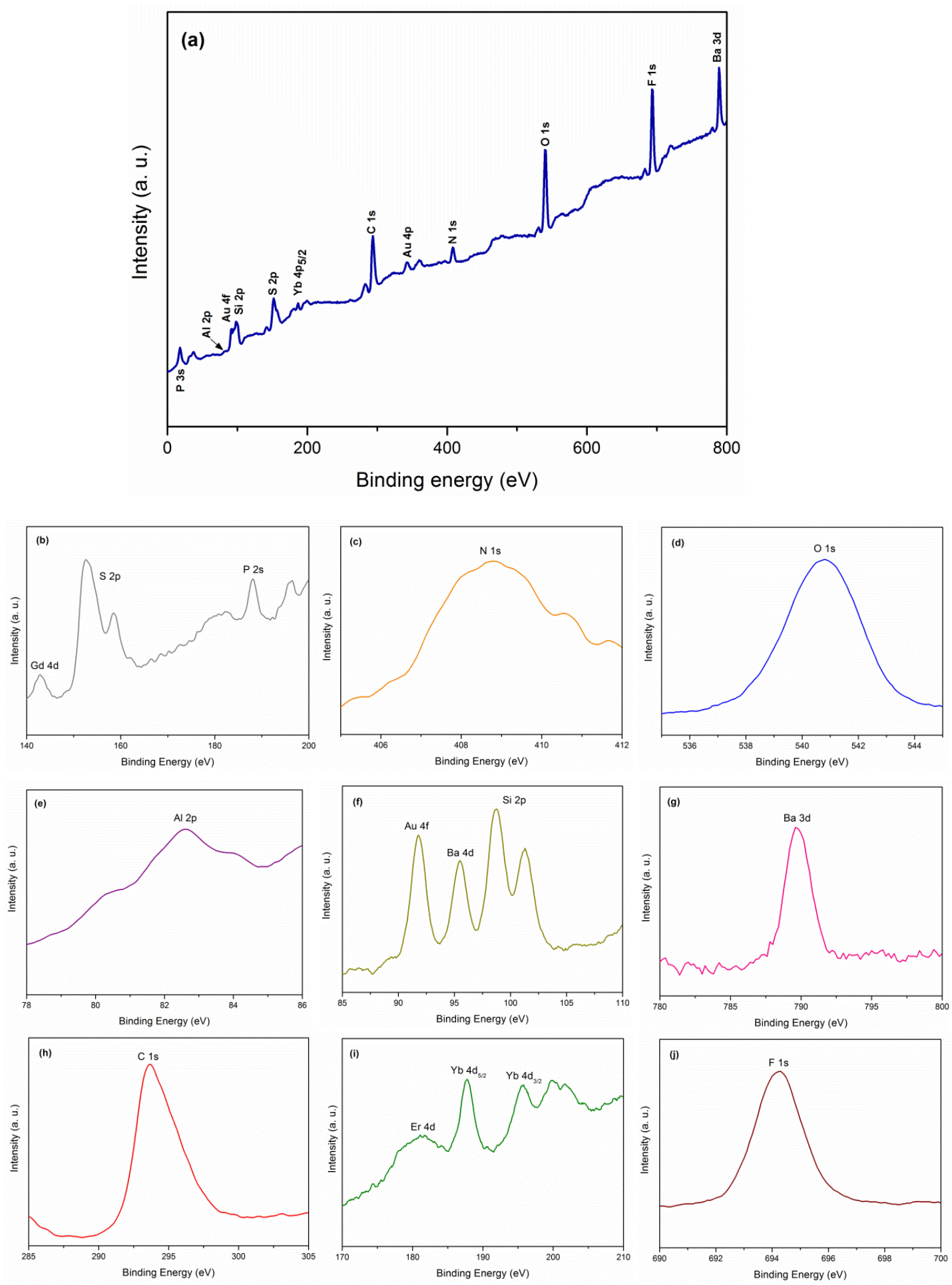

Figure S8. (a) XPS wide scan of the UCNPs-probe-Ebola virus oligo-AuNPs on NAAO substrate; (b)-(j) HR-XPS scan of different energy ranges, showing the existence of individual elements in the heterogeneous assay. 


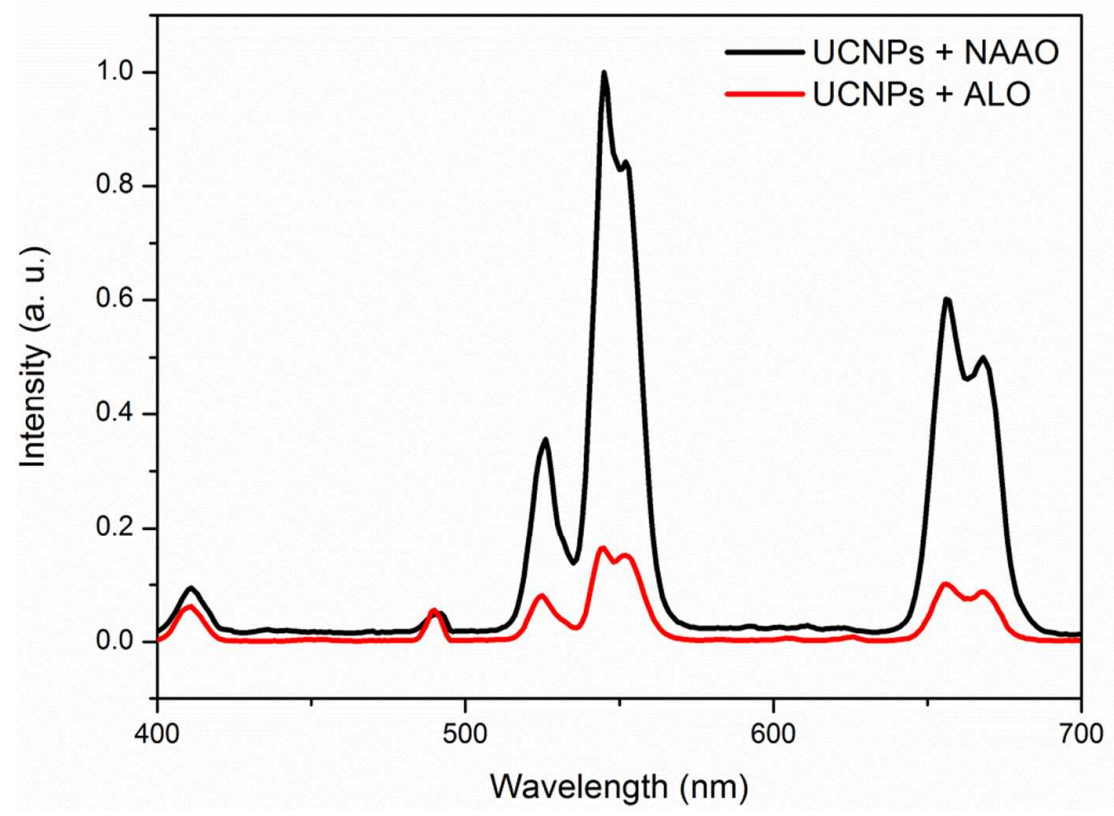

Figure S9. UCL emission enhancement of $\mathrm{BaGdF}_{5}: \mathrm{Yb} / \mathrm{Er}$ UCNPs anchored on NAAO membrane compared to that on ordinary aluminum oxide foil (ALO). 

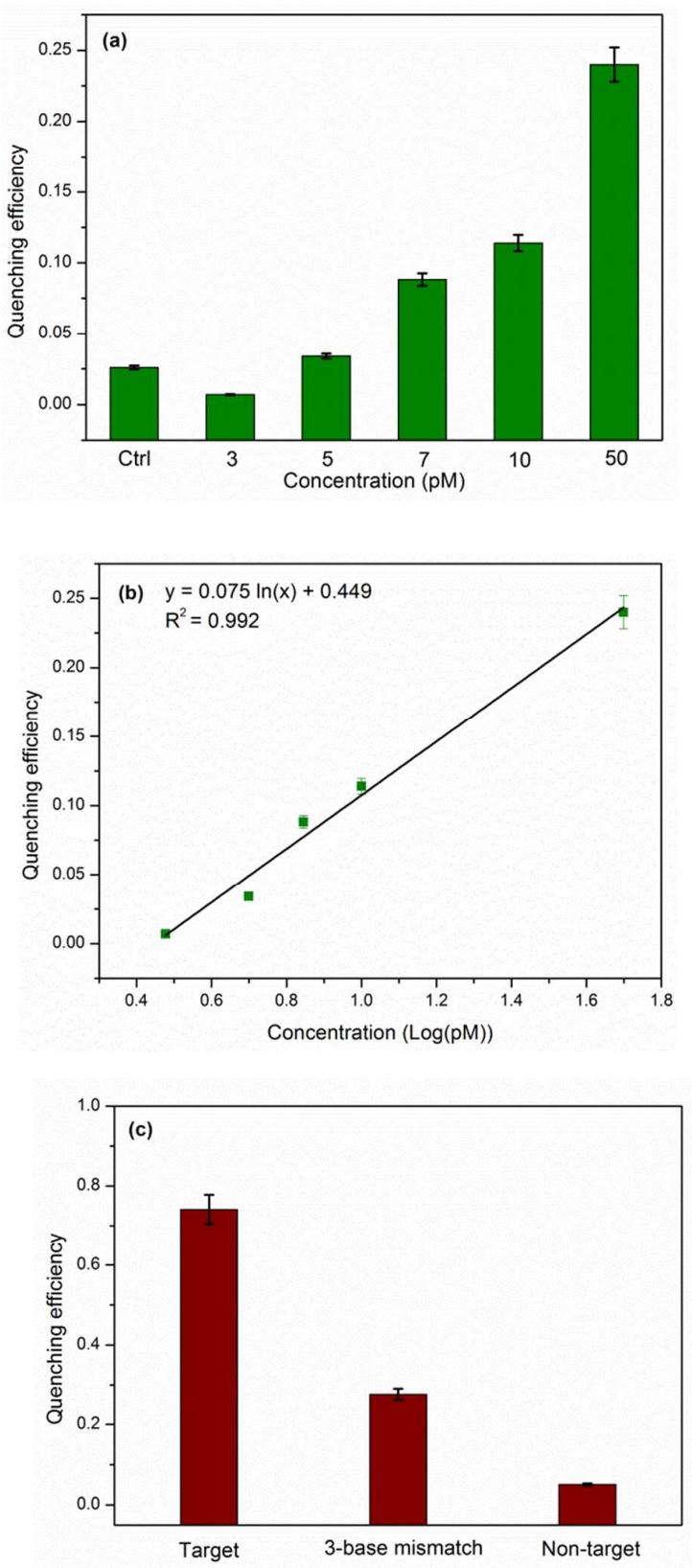

Figure S10. (a) UCL emission quenching measured from 3 to $50 \mathrm{pM}$ of Ebola virus oligo in the homogeneous assay; (b) Linear relationship of the homogeneous assay for Ebola virus oligo and (c) Specificity test for the homogeneous assay based on a 3-bases mismatch oligo and a non-complementary target at $3 \mathrm{nM}$ target concentration. 


\section{References}

(1) Ye, W. W.; Tsang, M.-K.; Liu, X.; Yang, M.; Hao, J. Upconversion Luminescence Resonance Energy Transfer (LRET)-Based Biosensor for Rapid and Ultrasensitive Detection of Avian Influenza Virus H7 Subtype. Small 2014, 10, 2390-2397.

(2) Sanchez, A.; Ksiazek, T. G.; Rollin, P. E.; Miranda, M. E. G.; Trappier, S. G.; Khan, A. S.; Peters, C. J.; Nichol, S. T. Detection and Molecular Characterization of Ebola Viruses Causing Disease in Human and Nonhuman Primates. J. Infect. Dis. 1999, 179, S164-S169.

(3) Ye, W.; Guo, J.; Chen, S.; Yang, M. Nanoporous Membrane Based Impedance Sensors to Detect the Enzymatic Activity of Botulinum. J. Mater. Chem. B 2013, 1, 6544-6550.

(4) Ye, W. W.; Shi, J. Y.; Chan, C. Y.; Zhang, Y.; Yang, M. A Nanoporous Membrane Based Impedance Sensing Platform for DNA Sensing with Gold Nanoparticle Amplification. Sensors Actuators B Chem. 2014, 193, 877-882.

(5) Karrasch, S.; Dolder, M.; Schabert, F.; Ramsden, J.; Engel, A. Covalent Binding of Biological Samples to Solid Supports for Scanning Probe Microscopy in Buffer Solution. Biophys. J. 1993, 65, 2437-2446.

(6) Wang, G.; Sun, Y.; Zhang, K.; Jia, T.; Hao, M.; Zhang, D.; Chang, L.; Zhang, L.; Zhang, R.; Lin, G.; et al. External Quality Assessment of Molecular Detection of Ebola Virus in China. PLoS One 2015, 10, e0132659.

(7) Tsang, M.-K.; Chan, C.-F.; Wong, K.-L.; Hao, J. Comparative Studies of Upconversion Luminescence Characteristics and Cell Bioimaging Based on One-Step Synthesized Upconversion Nanoparticles Capped with Different Functional Groups. $J$. Lumin. 2015, 157, 172-178. 
(8) Zeng, S.; Tsang, M.-K.; Chan, C.-F.; Wong, K.-L.; Fei, B.; Hao, J. Dual-Modal Fluorescent/magnetic Bioprobes Based on Small Sized Upconversion Nanoparticles of Amine-Functionalized $\mathrm{BaGdF}_{5}: \mathrm{Yb} /$ Er. Nanoscale 2012, 4, 5118-5124.

(9) Alex, S.; Dupuis, P. FT-IR and Raman Investigation of Cadmium Binding by DNA. Inorg. Cheimica Acta 1989, 157, 271-281.

(10) Zeng, S.; Yi, Z.; Lu, W.; Qian, C.; Wang, H.; Rao, L.; Zeng, T.; Liu, H.; Liu, H.; Fei, B.; et al. Simultaneous Realization of Phase/Size Manipulation, Upconversion Luminescence Enhancement, and Blood Vessel Imaging in Multifunctional Nanoprobes Through Transition Metal $\mathrm{Mn}^{2+}$ Doping. Adv. Funct. Mater. 2014, 24, 4051-4059. 